\title{
Wire-arc additive manufacturing of a duplex stainless steel: thermal cycle analysis and microstructure characterization
}

\author{
Vahid A Hosseini ${ }^{1}$ (D) Mats Högström ${ }^{1} \cdot$ Kjell Hurtig $^{1} \cdot$ Maria Asuncion Valiente Bermejo $^{1} \cdot$ Lars-Erik Stridh $^{1}$. \\ Leif Karlsson ${ }^{1}$
}

Received: 10 October 2018 / Accepted: 17 March 2019 / Published online: 9 April 2019

(C) The Author(s) 2019

\begin{abstract}
The evolution of microstructures with thermal cycles was studied for wire-arc additive manufacturing of duplex stainless steel blocks. To produce samples, arc energy of $0.5 \mathrm{~kJ} / \mathrm{mm}$ and interlayer temperature of $150{ }^{\circ} \mathrm{C}$ were used as low heat input-low interlayer temperature (LHLT) and arc energy of $0.8 \mathrm{~kJ} / \mathrm{mm}$ and interlayer temperature of $250{ }^{\circ} \mathrm{C}$ as high heat input-high interlayer temperature (HHHT). Thermal cycles were recorded with different thermocouples attached to the substrate as well as the built layers. The microstructure was analyzed using optical and scanning electron microscopy. The results showed that a similar geometry was produced with 14 layers - 4 beads in each layer - for LHLT and 15 layers - 3 beads in each layer-for HHHT. Although the number of reheating cycles was higher for LHLT, each layer was reheated for a shorter time at temperatures above $600{ }^{\circ} \mathrm{C}$, compared with HHHT. A higher austenite fraction $(+8 \%)$ was achieved for as-deposited LHLT beads, which experienced faster cooling between 1200 and $800{ }^{\circ} \mathrm{C}$. The austenite fraction of the bulk of additively manufactured samples, reheated several times, was quite similar for LHLT and HHHT samples. A higher fraction of secondary phases was found in the HHHT sample due to longer reheating at a high temperature. In conclusion, an acceptable austenite fraction with a low fraction of secondary phases was obtained in the bulk of wire-arc additively manufactured duplex stainless steel samples (35-60\%), where higher austenite fractions formed with a larger number of reheating cycles as well as longer reheating at high peak temperatures $\left(800-1200{ }^{\circ} \mathrm{C}\right)$.
\end{abstract}

Keywords Duplex stainless steels $\cdot$ Additive manufacturing $\cdot$ GMAW $\cdot$ Thermal cycles $\cdot$ Austenite fraction $\cdot$ Secondary phases

\section{Introduction}

Duplex stainless steels (DSS) have a wide range of applications due to their excellent combination of superior mechanical properties and high corrosion resistance [1]. The main DSS fabrication route is arc welding of flat and tubular products [2]; however, casting is also common for the production of complex geometries [3-6]. To produce near-net shape components, powder metallurgy is also applicable for complex geometries [7]. Recently, additive manufacturing (AM) of

Recommended for publication by Commission II - Arc Welding and Filler Metals

Vahid A Hosseini

vahid.hosseini@hv.se

1 Department of Engineering Science, University West, SE-461 86 Trollhättan, Sweden
DSS has also been practiced using powder or wire as feedstock $[8,9]$.

Duplex stainless steels have a ferritic-austenitic microstructure [10]. It has been claimed that the optimum properties of these alloys are achieved when the ferrite/austenite fraction is $50 / 50$ [11]. In fabrication processes, such as welding, casting, and most recently AM, a proper ferrite/ austenite fraction is one of the most important application requirements. Thermal cycle and chemical composition are two important factors governing the phase fraction in DSS. Nitrogen and nickel, as the most potent austenite-forming alloying elements in DSS, play an important role in the solid-state precipitation of austenite after the fully ferritic solidification of these steels [12]. To promote the austenite formation, high-nickel-content filler metals and/or nitrogencontaining shielding gas are used for welding of DSS $[2,13]$. Slow cooling promotes the austenite precipitation; however, it may cause the precipitation of deleterious secondary phases, such as sigma, chi, nitrides, and carbides [14]. 
Rapid cooling, in contrast, not only restricts austenite formation but also causes the precipitation of non-equilibrium nitrides $[15,16]$. Therefore, a correct selection of process parameters is a key factor to fabricate a balanced DSS microstructure. In single-pass welding, experiencing a single thermal cycle, the guidelines to define the process parameters have been well-established [2, 11, 17]. However, the process parameters for more complex thermal cycles, such as the AM process, are still unknown for the fabrication of DSS products.

AM of metallic alloys has become a promising near-net shape material fabrication route. Metal AM can be classified as powder bed, powder feed, and wire feed systems [18]. In powder bed systems, the powder is added to the top of the substrate and melted using electron beam (EBM) or laser (SLM). They have high-dimensional control and design freedom, but a low production rate. In powder feed systems, the powder is added to the surface with a nozzle during application of the energy. The deposition rate is higher than that for powder bed fusion. In wire feed systems, the feedstock is a wire, and the energy source can be an electron beam, laser, or electric arc. The system is suitable for high deposition rates and large build volumes with a lower investment cost; however, the product needs more final machining [19].

Few studies have investigated AM of duplex stainless steels. Davidson et al. [9] fabricated type-2507 super duplex stainless steels using SLM. The as-built piece contained 93\% ferrite with some $\mathrm{Cr}_{2} \mathrm{~N}$ particles. Heat treatment at $1040{ }^{\circ} \mathrm{C}$ decreased ferrite fraction to 55\%. Hengsbach et al. [20] produced a type-2205 DSS piece with SLM, where they got 99\% ferrite fraction, while heat treatment at $1000{ }^{\circ} \mathrm{C}$ decreased the ferrite fraction to $66 \%$. Posch et al. [8] investigated wire-arc AM (WAAM) of DSS using type-2209 filler metal and coldmetal transfer (CMT) process. This technique produced a sample with a microstructure having an as-built ferrite number of $30 \mathrm{FN}$ and mechanical properties comparable with those from the filler metal certificate. Eriksson et al. [21] also studied the CMT process to additively manufacture super duplex stainless steels, where a ferrite fraction of $20 \%$ and acceptable mechanical properties were achieved.

Based on the previous studies, WAAM has very good potential to produce DSS with proper mechanical properties and microstructure. In addition to the production of the entire component, it is possible to add various DSS components to the main piece where a high-performance alloy is needed. However, the development of microstructures with thermal cycles is still unknown for WAAM of DSS. The next possible step toward WAAM of DSS is to find the relationship between heat input and interlayer temperature with thermal cycles and microstructures. The aim of the present study is, therefore, to record the thermal cycles and correlate them with the as-built microstructure in WAAM of type-2209 DSS using the gasmetal arc welding (GMAW) process.

\section{Experimental}

Type-2209 welding wire was used for the experiment. The chemical composition of the welding wire is detailed in Table 1.

Two blocks with the size of $120 \mathrm{~mm} \times 30 \mathrm{~mm} \times 27 \mathrm{~mm}$ were deposited on a type- 2205 duplex stainless steel plate using a Fronius VR7000CMT MIG welding machine and an ABB 1400 robot. Pure argon was used as shielding gas. Two different sets of process parameters were employed to produce the blocks: low heat input (the arc energy of $0.5 \mathrm{~kJ} / \mathrm{mm}$ )-low interlayer temperature $\left(150^{\circ} \mathrm{C}\right)$ and high heat input (the arc energy of $0.8 \mathrm{~kJ} / \mathrm{mm})$-high interlayer temperature $\left(250^{\circ} \mathrm{C}\right)$. A voltage of $24.5 \mathrm{~V}$, a current of $147 \mathrm{~A}$, and a welding speed of $6.5 \mathrm{~mm} / \mathrm{s}$ were used for low arc heat input, and a voltage of $24.8 \mathrm{~V}$, a current of $170 \mathrm{~A}$, and a welding speed of $5 \mathrm{~mm} / \mathrm{s}$ were used for high arc heat input. A pre-test was performed to find the suitable build path, where one-direction and alternating direction paths were studied.

To record the thermal cycles, three type-K thermocouples were attached on the top of the substrate as shown in Fig. 1. In addition, after the deposition of layer 7, two other type-K thermocouples were attached on the top by drilling holes from the back side of each plate. Before fabrication, the specimens were heated up to the selected interlayer temperatures using an electrical heater. Finally, a thermocouple was harpooned into the melt pool of the last deposited bead.

To investigate the evolution of the microstructure, austenite fractions of as-deposited and one-time-reheated microstructures were measured using an image analysis technique. In addition, the austenite fractions along two lines under the last deposited layer were studied (Fig. 1). Modified Beraha with a chemical composition of $60 \mathrm{ml}$ water, $30 \mathrm{ml} \mathrm{HCl}$, and $0.75 \mathrm{~g}$ potassium bisulfite was used to etch the cross sections for austenite fraction measurement. The austenite fraction was measured using the image analysis technique using ImagePro software. More details about the technique were discussed in reference [22].

To find possible secondary phase precipitates, the cross sections were electrolytically etched using $7 \%$ oxalic acid with $4 \mathrm{~V}$ and $10 \mathrm{~s}$ followed by $40 \% \mathrm{NaOH}$ with $2 \mathrm{~V}$ and $10 \mathrm{~s}$. In addition, the as-polished sample was studied with a Hitachi scanning electron microscope (SEM) using the backscattered electron (BSE) mode.

Table 1 Chemical composition (wt\%) of the welding wire according to the manufacturer's certificate

\begin{tabular}{llllllllll}
\hline & $\mathrm{C}$ & $\mathrm{Si}$ & $\mathrm{Mn}$ & $\mathrm{Cr}$ & $\mathrm{Ni}$ & $\mathrm{Mo}$ & $\mathrm{N}$ & $\mathrm{Cu}$ & $\mathrm{Fe}$ \\
\hline $\begin{array}{c}\text { Filler } \\
\text { metal }\end{array}$ & 0.012 & 0.48 & 1.55 & 23.01 & 8.64 & 3.10 & 0.16 & 0.05 & Balance \\
\hline
\end{tabular}


Fig. 1 The placement of thermocouples and locations to study the microstructure: low heat input-low temperature (LHLT) to the left and high heat input-high temperature (HHHT) to the right. As-deposited and one-time reheated refer to the last bead and second to the last bead, respectively

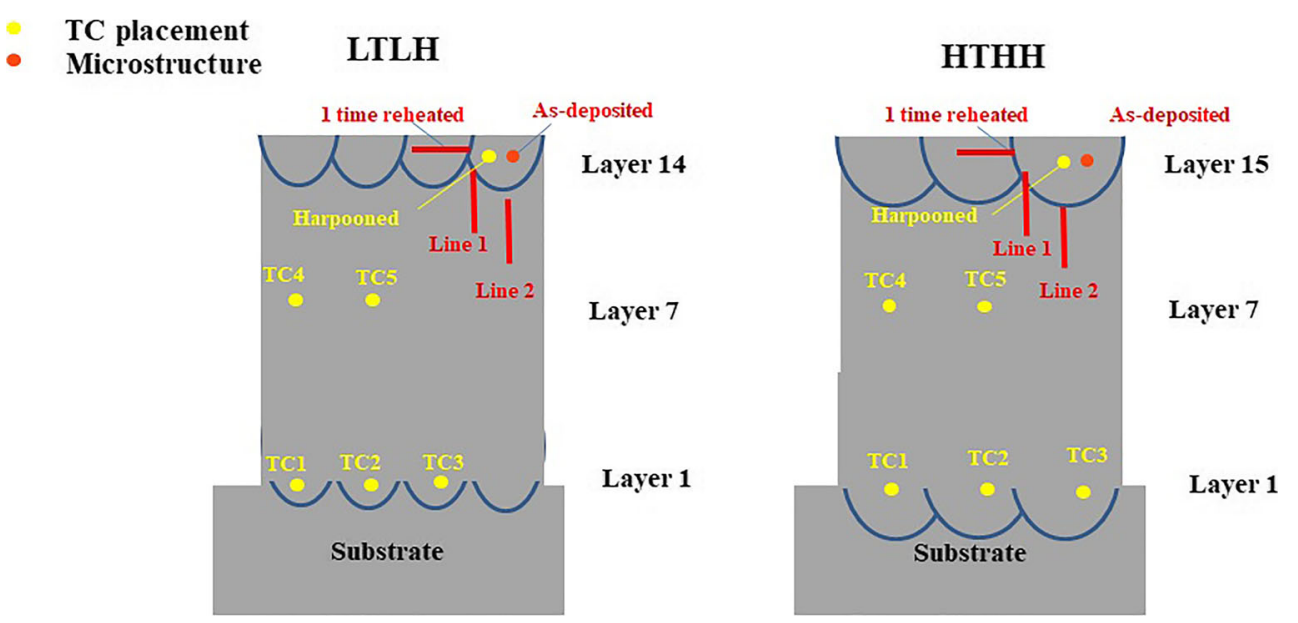

Equilibrium phase fractions were calculated for the welding wire chemical composition with different nitrogen contents $(0.16 \mathrm{wt} \%$ as mentioned in the certificate and $0.1 \mathrm{wt} \%$ ) using JMatPro software package V6.2.1.

\section{Results}

\subsection{Appearance and cross section}

Preliminary results showed that a one-direction build path (Fig. 2a) produced uneven sides on the block, where the start side was higher than the end side. The heat accumulation at the stop point during the deposition of each layer was the reason for this observation. However, the alternating direction path produced an even height (Fig. 2b).
Macroimages of the samples produced with LHLT and HHHT are shown in Fig. 3. To produce a similar geometry, 14 layers and 4 beads in each layer for LHLT and 15 layers and 3 beads in each layer for HHHT were deposited. Increasing the heat input and interlayer temperature, therefore, did not change the number of layers significantly, but it reduced the total number of passes. As shown in Fig. 1, it can be seen that HHHT melted the substrate more than LHLT did, and the weld pool was bigger (see substratebuilt interface).

A typical cross section of a sample etched with modified Beraha is shown in Fig. 4. The cross section showed some porosities/lack of fusion, particularly between the beads. In the sample etched with modified Beraha, the darker and brighter area contains more ferrite and austenite, respectively. As may be seen, the microstructure shows a pattern with the
Fig. 2 Wire-based additively manufactured DSS blocks a uneven height produced with one direction path $\mathbf{b}$ even height produced with alternating direction path
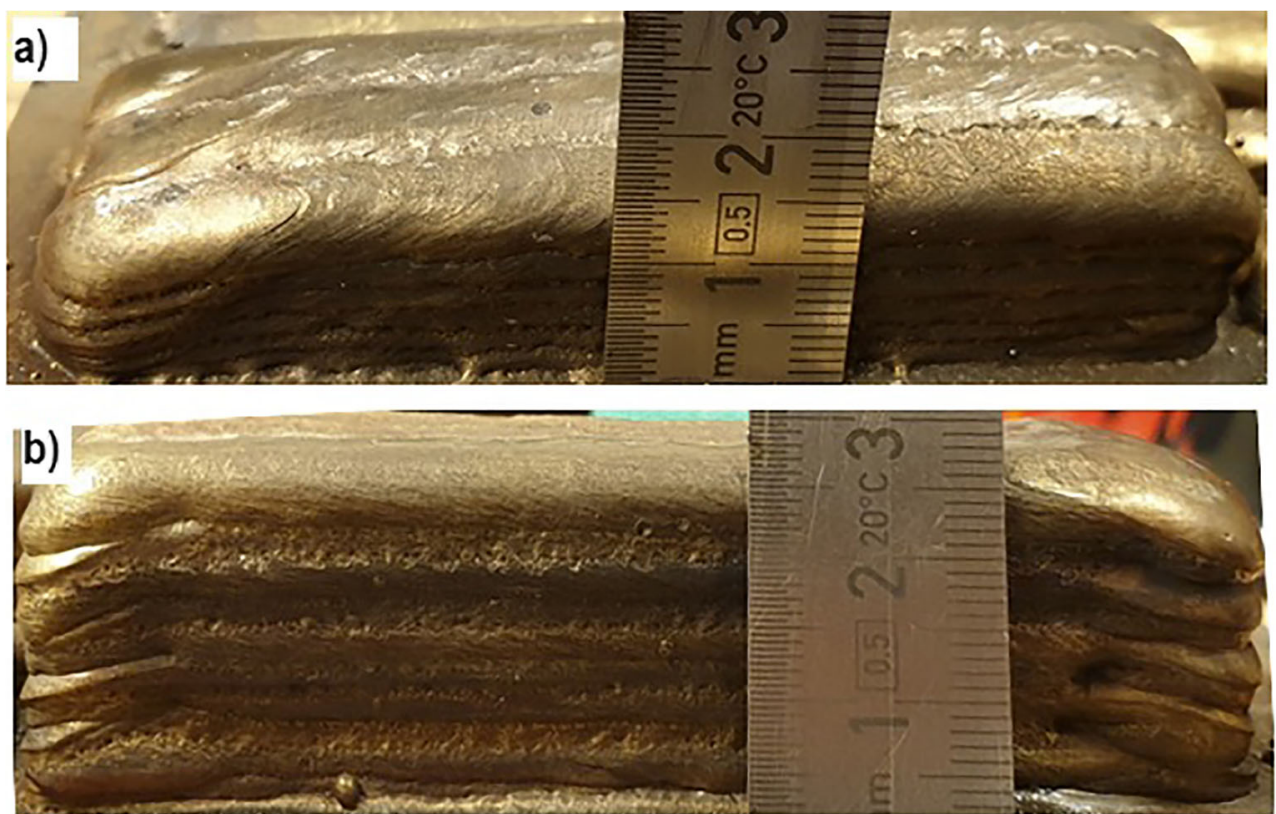
Fig. 3 Macroimages of LHLT and HHHT samples. LHLT and HHHT samples have 4 and 3 beads in each layer, respectively
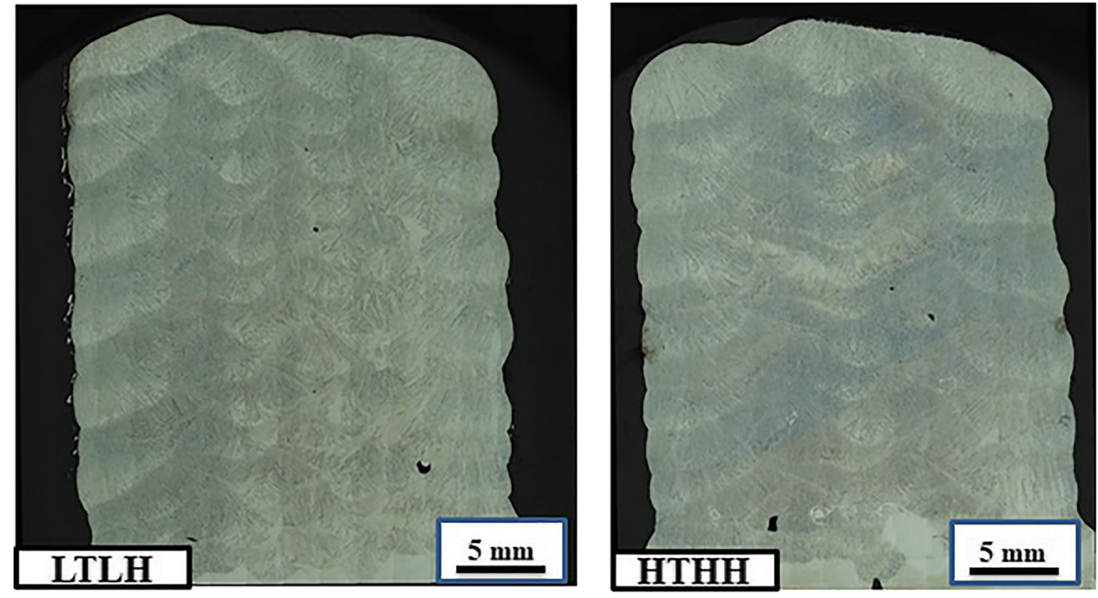

bright to dark etching, as shown with lines 1 and 2 in Fig. 4, where the amount of austenite slightly decreased from the regions located between the beads (line 1) toward the region located under the beads (line 2). The pattern was similar for both samples. The detailed characterization of microstructure for these regions is presented in Sect. 3.3.

\subsection{Thermal cycles}

Thermal cycles for LHLT and HHHT samples are shown in Figs. 5 and 6, respectively. The thermal cycles of all deposited layers were successfully recorded with the thermocouples. Looking closer at the thermal cycles shows that deposition of each layer produced 4 and 3 distinctive peak temperatures for LHLT and HHHT samples, respectively. Each peak temperature indicates the deposition of one bead.

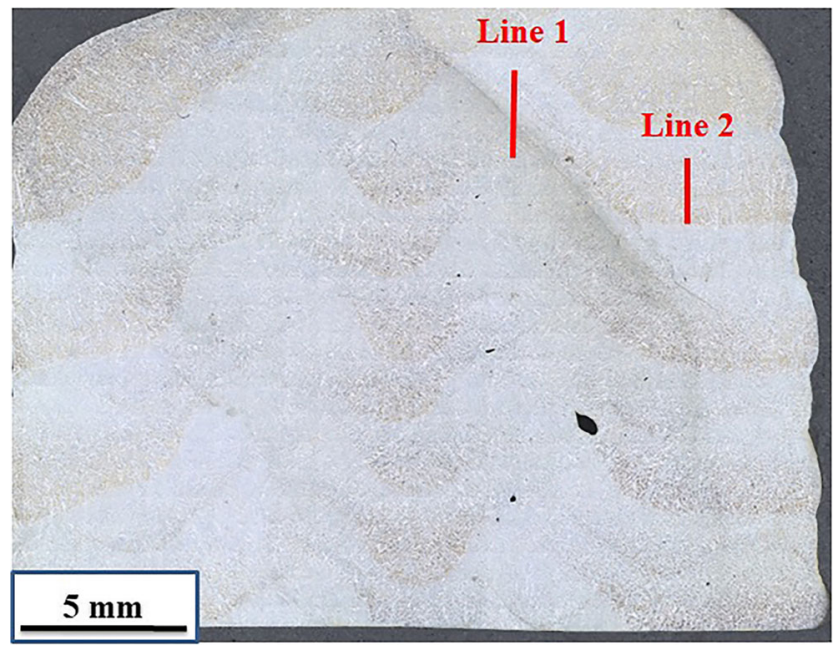

Fig. 4 Typical cross section of additively manufactured type-2205 DSS samples. The darker area is more ferritic and the brighter more austenitic. A pattern can be seen in the bulk of the built sample, where lines 1 and 2 show the brightest and darkest etched regions
The peak temperatures recorded by each thermocouple for deposition of layers 1, 2, 7, and 8 are shown in Table 2 for LHLT and Table 3 for HHHT. When the thermocouple was closer to the deposited bead, for instance, layers 1, 2, and 3, the highest peak temperature of each thermocouple was achieved when the bead was deposited on the top of the thermocouple. However, as the distance from the thermocouples increased (for instance 9 layers, as shown in Figs. 5 and 6), the highest peak temperature was recorded when the last bead in each layer was deposited. A comparison of different thermocouples placed in the same layer shows that the highest peak temperature for each pass is always recorded for the thermocouple located under the current pass.

The peak temperatures measured by the thermocouples at the interface between the substrate and the build were above $600{ }^{\circ} \mathrm{C}$ for up to 3 layers for the LHLT sample, but up to 5 layers for the HHHT sample. For thermocouples attached on layer 7 , the peak temperature was above $600{ }^{\circ} \mathrm{C}$ until 4 layers for the LHLT sample, but 6 layers for the HHHT samples. This showed that the peak temperature isotherms became wider at locations higher up in the built material.

The total fabrication times were $183 \mathrm{~min}$ for LHLT and $110 \mathrm{~min}$ for HHHT. As shown in Table 4, the time of each layer at temperatures above $400{ }^{\circ} \mathrm{C}\left(\Delta t_{>400}\right)$ was $151 \mathrm{~s}$ at the bottom and $178 \mathrm{~s}$ in the middle of the LHLT sample. This time is $167 \mathrm{~s}$ at the bottom and $200 \mathrm{~s}$ in the middle of the HHHT sample. It was therefore seen that the HHHT sample experienced a longer $\Delta t_{>400}$, but the production time was longer for the LHLT sample due to the lower interlayer temperature. In addition, both samples experienced longer $\Delta t_{>400}$ for the thermocouples attached on layer 7 than those attached on layer 1 .

The cooling time from 1200 to $800{ }^{\circ} \mathrm{C}\left(\Delta t_{1200-800}\right)$ is detailed in Table 4 for each as-deposited bead on layers 1 and 7. The cooling times for the HHHT sample were always larger than those for the LTLH sample. Increasing the number of 
Fig. 5 Thermal cycles recorded for LTLH samples. " $L$ " stands for layer and " $B$ " for bead. Thermal cycles are for the interlayer temperature of $150{ }^{\circ} \mathrm{C}$ and 4 beads in each layer

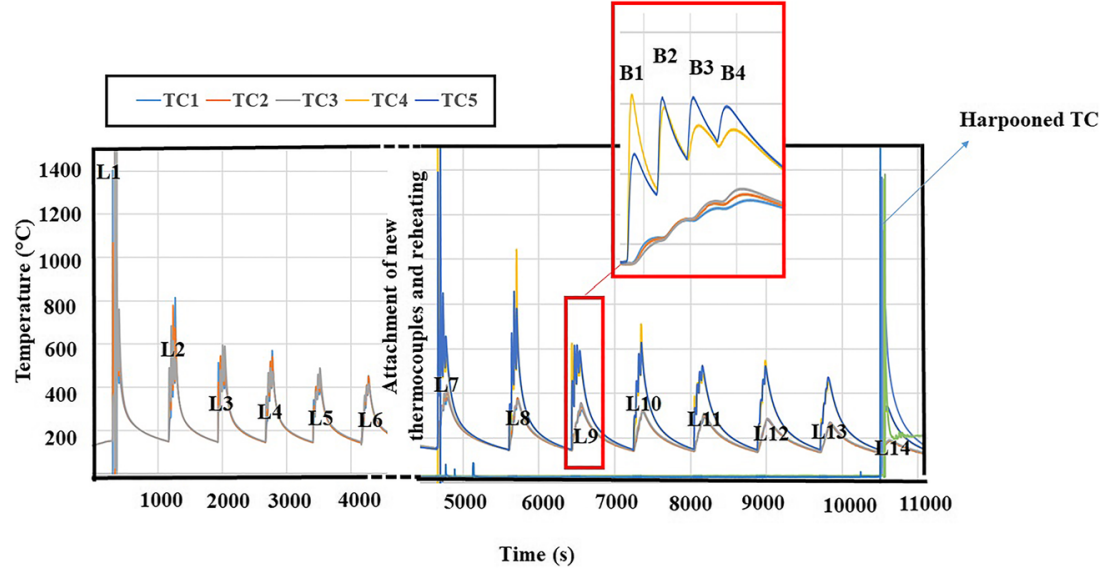

beads in each layer increased $\Delta t_{1200-800}$, which was more pronounced for layer 1 . No obvious changes in the cooling time were observed for the beads between layers 1 and 7 , while $\Delta t_{>400}$ was longer for the thermocouples attached on layer 7 in both samples than those attached on layer 1.

\subsection{Microstructure}

\subsubsection{As-deposited beads}

The microstructure of as-deposited beads in LHLT and HHHT samples is shown in Fig. 7. The microstructure has a ferritic matrix with mostly grain boundary and Widmanstätten austenite. The austenite fraction of as-deposited metal is $46 \pm 2$ for LHLT and $38 \pm 2$ for HTHH.

\subsubsection{One-time-reheated beads}

As, in the present study, one of the important aims is to find the evolution of the additively manufactured DSS microstructure with addition of further beads, the influence of the first reheating pass on the as-deposited bead is shown in Fig. 8 for LHLT and in Fig. 9 for HHHT at different distances from the fusion boundary (interface) of the next bead.

In the LHLT sample, as shown in Fig. 8, adding the new bead changed the microstructure of the previously deposited bead. Very close to the interface between the new as-deposited and the one-time-reheated beads, a region with a high ferrite fraction is formed. From 0.4 to $1.6 \mathrm{~mm}$, mostly the growth of primary austenite compared with as-deposited bead was observed (Fig. 7a). From this location to $4.4 \mathrm{~mm}$, secondary austenite grains also formed. The secondary austenite was much finer at larger distances from the fusion boundary. It should be noted that the secondary austenite in this paper was only referred to the intragranular austenite grains forming during reheating.

Similar microstructural changes as those observed for the LHLT samples were found for the HHHT sample; however, the extent of the changes was much larger for this sample. As may be seen in Fig. 9, the secondary austenite precipitated up
Fig. 6 Thermal cycles recorded for HTHH samples. Thermal cycles are for the interlayer temperature of $250{ }^{\circ} \mathrm{C}$ and 3 beads in each layer

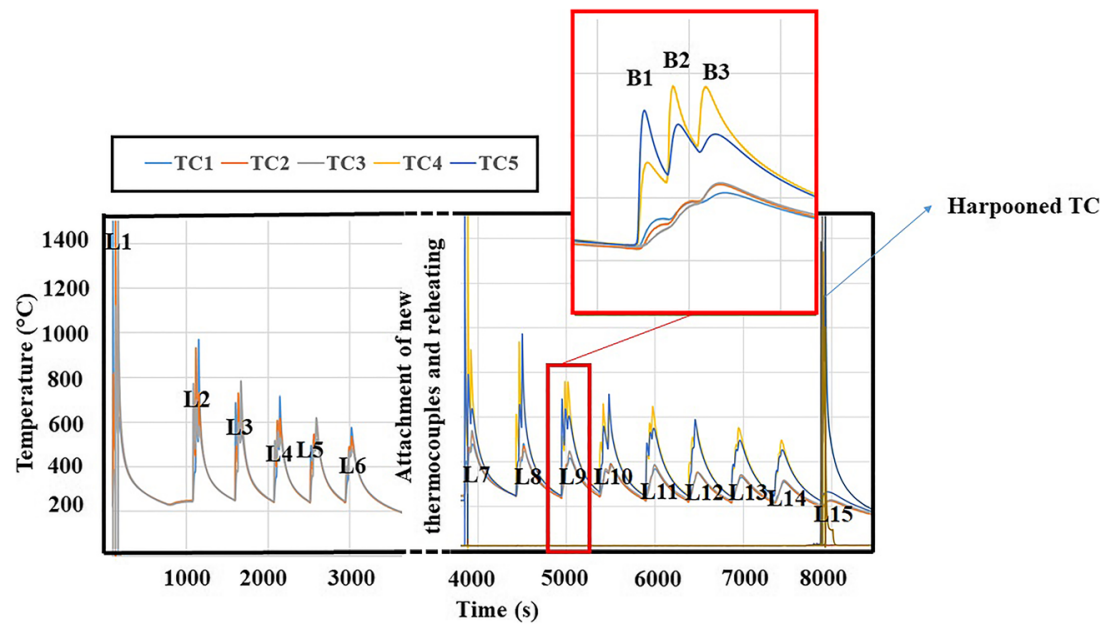


Table 2 Peak temperatures recorded with thermocouples for the LHLT sample

$\mathrm{TC} 1\left({ }^{\circ} \mathrm{C}\right) \quad \mathrm{TC} 2\left({ }^{\circ} \mathrm{C}\right) \quad \mathrm{TC} 3\left({ }^{\circ} \mathrm{C}\right) \quad \mathrm{TC} 4\left({ }^{\circ} \mathrm{C}\right) \quad \mathrm{TC} 5\left({ }^{\circ} \mathrm{C}\right)$

\begin{tabular}{lccccc}
\hline L1-B1 & Melt & 1043 & 357 & NA & NA \\
L1-B2 & 701 & Melt & Melt & NA & NA \\
L1-B3 & 505 & 792 & Melt & NA & NA \\
L1-B4 & 453 & 542 & 728 & NA & NA \\
L2-B1 & 252 & 383 & 488 & NA & NA \\
L2-B2 & 403 & 679 & 672 & NA & NA \\
L2-B3 & 671 & 799 & 608 & NA & NA \\
L2-B4 & 803 & 676 & 520 & NA & NA \\
L7-B1 & 275 & 238 & 234 & Melt & 1390 \\
L7-B2 & 337 & 337 & 337 & 821 & Melt \\
L7-B3 & 381 & 399 & 381 & 600 & 827 \\
L7-B4 & 378 & 408 & 433 & 551 & 652 \\
L8-B1 & 222 & 238 & 235 & 277 & 352 \\
L8-B2 & 286 & 297 & 300 & 460 & 670 \\
L8-B3 & 335 & 345 & 345 & 736 & 822 \\
L8-B4 & 369 & 369 & 369 & 1020 & 787 \\
\hline
\end{tabular}

NA not applicable

to $7.2 \mathrm{~mm}$ from the interface. In addition, the secondary austenite grains precipitating at higher temperatures were slightly coarser in the HHHT sample.

The austenite fraction after one-time reheating at different distances from the interface of as-deposited and one-timereheated beads is shown in Fig. 10 for the LHLT and HHHT samples. The austenite fraction next to the interface was about $10 \%$ lower compared with the as-deposited condition in both samples. With larger distances from the interface, the austenite fraction increased. Generally, the level of austenite fraction was higher for the LHLT sample. After about $3.6 \mathrm{~mm}$, the

Table 3 Peak temperatures recorded with thermocouples for the HHHT sample

\begin{tabular}{llllll}
\hline & $\mathrm{TC} 1\left({ }^{\circ} \mathrm{C}\right)$ & $\mathrm{TC} 2\left({ }^{\circ} \mathrm{C}\right)$ & $\mathrm{TC} 3\left({ }^{\circ} \mathrm{C}\right)$ & $\mathrm{TC} 4\left({ }^{\circ} \mathrm{C}\right)$ & $\mathrm{TC} 5\left({ }^{\circ} \mathrm{C}\right)$ \\
\hline L1-B1 & Melt & 806 & 620 & NA & NA \\
L1-B2 & 841 & Melt & 887 & NA & NA \\
L1-B3 & 378 & 1117 & Melt & NA & NA \\
L2-B1 & 371 & 670 & 770 & NA & NA \\
L2-B2 & 700 & 710 & 693 & NA & NA \\
L2-B3 & 987 & 580 & 573 & NA & NA \\
L7-B1 & 402 & 366 & 313 & 640 & 780 \\
L7-B2 & 463 & 463 & 432 & 800 & Melt \\
L7-B3 & 476 & 572 & 573 & Melt & 893 \\
L8-B1 & 337 & 347 & 347 & 400 & 580 \\
L8-B2 & 394 & 394 & 394 & 650 & 930 \\
L8-B3 & 465 & 465 & 438 & 970 & 760 \\
\hline
\end{tabular}

NA not applicable
Table 4 Details about times in different temperature ranges

\begin{tabular}{lccccc}
\hline Location & \multicolumn{2}{l}{ LHLT } & & \multicolumn{2}{l}{ HHHT } \\
\cline { 2 - 3 } \cline { 5 - 6 } \cline { 5 - 6 } & $\Delta t_{1200-800}(\mathrm{~s})$ & $\Delta t_{>400}(\mathrm{~s})$ & & $\Delta t_{1200-800}(\mathrm{~s})$ & $\Delta t_{>400}(\mathrm{~s})$ \\
\hline L1-B1 & 4.7 & 151 & & 7.4 & 167 \\
L1-B2 & 5.9 & & & 7.9 & \\
L1-B3 & 6.8 & & & 11.7 & \\
L1-B4 & - & & & NA & \\
L7-B1 & 4.7 & 176 & & - & 200 \\
L7-B2 & 4.9 & & & 8.3 & \\
L7-B3 & - & & & 8.9 & \\
L7-B4 & - & & & NA & \\
\hline
\end{tabular}

austenite fraction of the LHLT sample met the as-deposited austenite fraction. For the HHHT sample, however, it was still about $9 \%$ higher than that for the as-deposited fraction - up to $5 \mathrm{~mm}$ from the interface. It, therefore, can be concluded that the higher heat input and interlayer temperature caused an increase in austenite fraction at longer distances from the fusion boundary in the one-time-reheated bead.

\subsubsection{Microstructure in the bulk}

As described in Sect. 3.1, the microstructure in the bulk of the additively manufactured samples followed a pattern. Therefore, characterization of the microstructure in the center and at a corner of a bead in the bulk of the samples, as shown with lines 1 and 2 in Fig. 4, provides information about the borders of this pattern for each sample.

Line 1 The microstructure along line 1 for the LHLT and HHHT samples is shown in Figs. 11 and 12, respectively. The $0 \mathrm{~mm}$ is located in a bead in the second bead from the top, where two beads from the top layer are deposited on it, as shown in Fig. 1.

In the LHLT sample, as shown in Fig. 11, the microstructure contains a mixture of primary and secondary austenite at $0 \mathrm{~mm}$. In about the first $3 \mathrm{~mm}$ from the top side of the bead, growth of primary austenite was mostly observed. At the bottom of the bead at line 1, secondary austenite appeared between primary austenite grains.

In HHHT samples, as shown in Fig. 12, the microstructure was mostly similar to the LHLT sample, except the growth of primary austenite was also observed at longer distances (5.2 mm).

The evolution of austenite fraction along line 1 is shown in Fig. 13. The austenite fraction at further distances from the top of the studied bead is higher for the HHHT sample; however, for the as-deposited sample, it was much lower than that in the LHLT sample. The maximum austenite fraction reached 55\% for the LHLT sample and $60 \%$ for the HHHT sample. 
Fig. 7 Microstructure of asdeposited filler metal. The LHLT sample contains more austenite than the HHHT sample
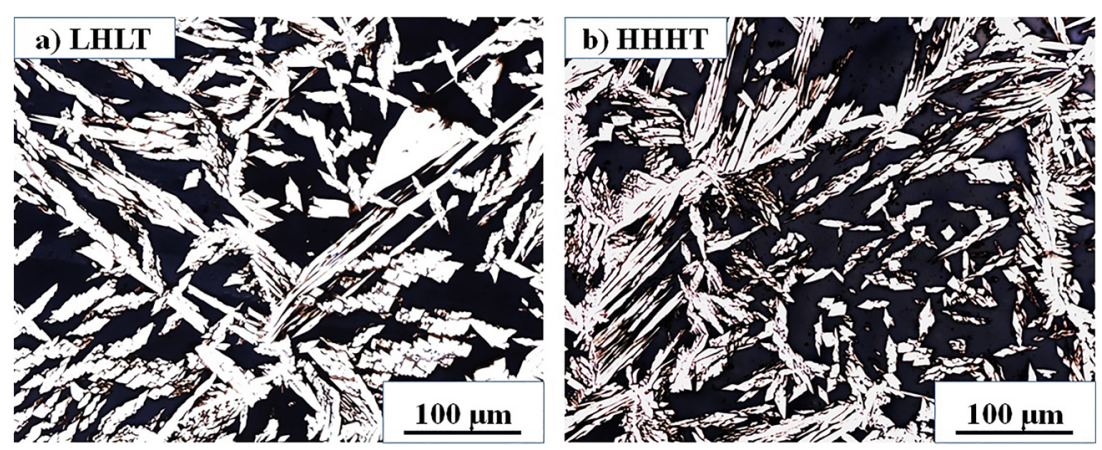

Fig. 8 Microstructure at different distances from the fusion boundary for the bead reheated one time in the LHLT sample. Growth of primary austenite and formation of secondary austenite can be seen at shorter and longer distances, respectively

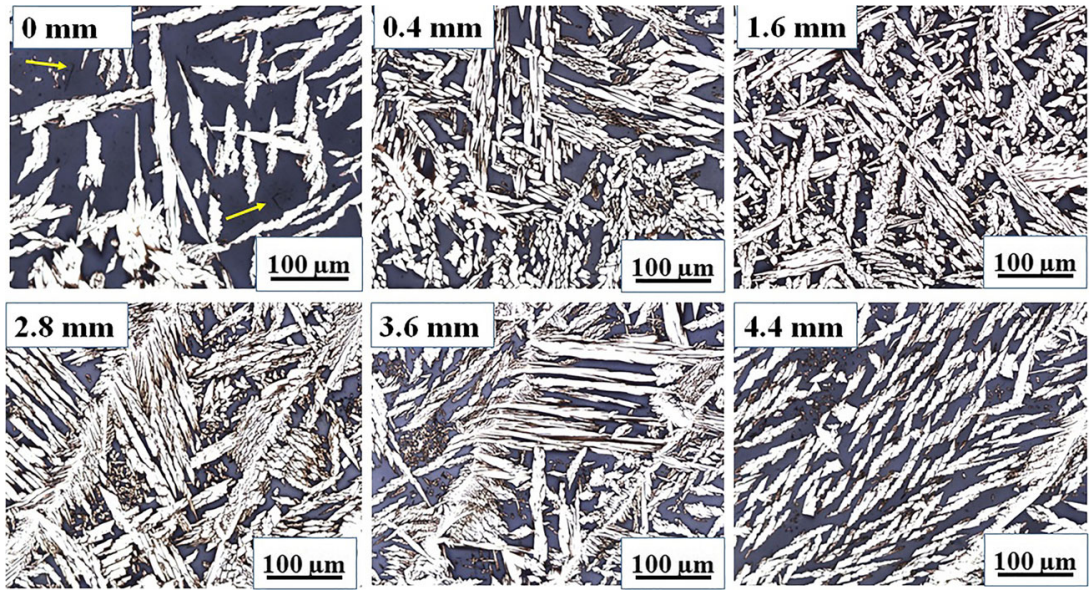

Line 2 The microstructures of the LHLT and HHHT samples along line 2 (shown in Fig. 1), located below the interface of two beads detailed in Fig. 1, are shown in Figs. 14 and 15 , respectively. At locations close to the top of the bead $(0 \mathrm{~mm})$, the growth of primary austenite and formation of secondary austenite were not observed. In both cases, by getting further away from the interface, the growth of primary austenite was observed and continued with the precipitation of secondary austenite. Considering almost the same distance from the bead above, for example for
$4 \mathrm{~mm}$ along line 1 (Fig. 12) and $3.6 \mathrm{~mm}$ along line 2 (Fig. 14), the secondary austenite precipitated along line 2 is much finer than that formed along line 1 .

The evolution of austenite fraction along line 2 is shown in Fig. 16. The austenite fraction at the $0-\mathrm{mm}$ location is lower than that for the as-deposited LHLT and HHHT beads. In less than $1 \mathrm{~mm}$, the austenite fraction reached $45 \%$ in both samples. The level of austenite fraction is very similar for the LHLT and HHHT samples, except at $3.2 \mathrm{~mm}$, where it was about $6 \%$ higher for the LHLT sample.
Fig. 9 Microstructure at different distances from the fusion boundary for the bead reheated one time in the HHHT sample. Similar to that in the LHLT sample, the growth of primary austenite and formation of secondary austenite were seen at shorter and longer distances, respectively
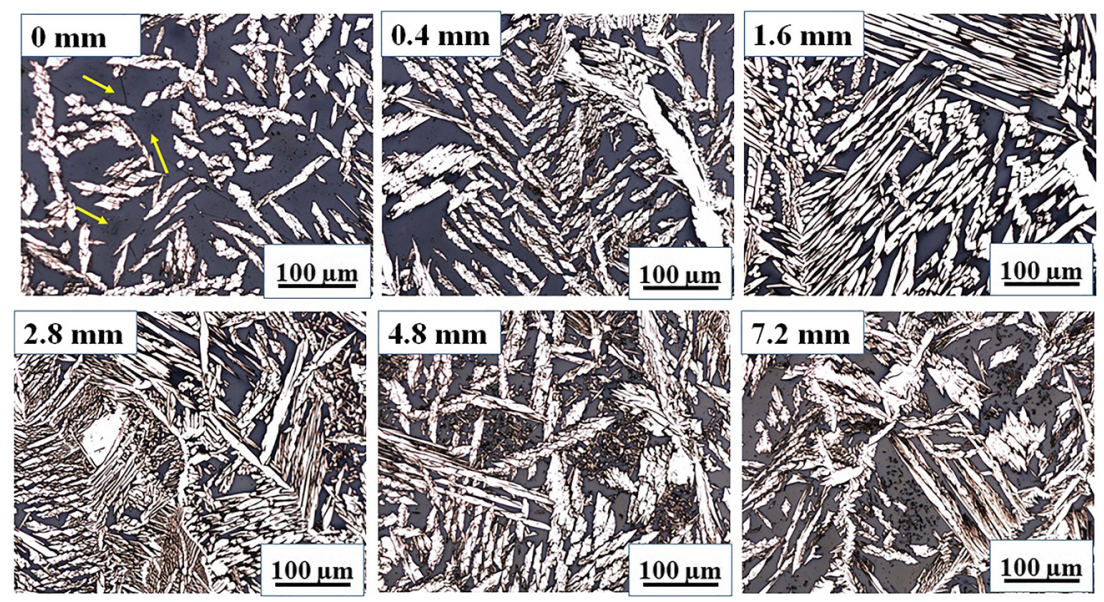


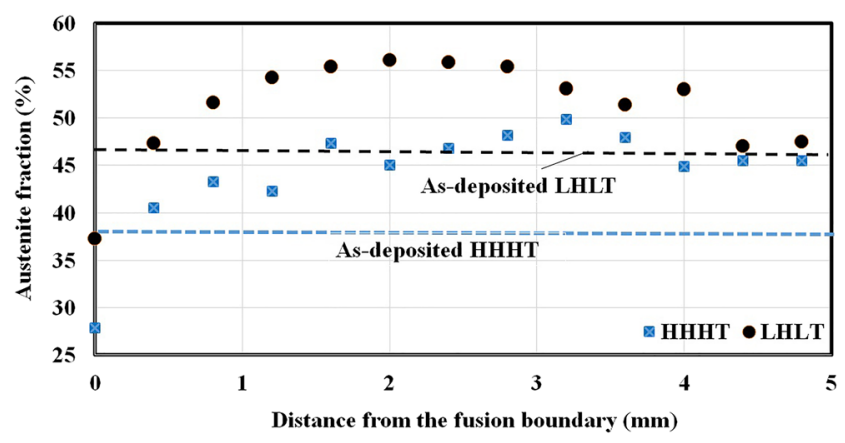

Fig. 10 Austenite fraction next to the as-deposited bead after one-time reheating. The austenite fraction of the LHLT sample is higher than that of the HHHT sample. The ferrite fraction of the LHLT sample achieved the as-deposited fraction after $4 \mathrm{~mm}$, but the ferrite fraction of the HHHT sample was still $10 \%$ higher than that of the as-deposited fraction even after $5 \mathrm{~mm}$

\subsubsection{Secondary phases}

As shown in Figs. 8 and 9, at $0 \mathrm{~mm}$ (very close to the fusion boundary of the one-time-reheated bead), some precipitates can be seen inside the ferrite in regions with a large austenite spacing. The fraction is seemingly higher in the HHHT sam- ple. They are mostly fine precipitates and in some cases precipitated next to each other on a line.

The microstructure of samples after two-step etching is shown in Fig. 17. In both samples, there is clearly precipitation of secondary phases at ferrite/austenite boundaries, where they have larger sizes and higher fractions in the HHHT sample compared with the LHLT sample.

A SEM micrograph of the HHHT sample is shown in Fig. 18. As the micrograph was taken with the backscattered mode, phases containing elements with a higher atomic weight are imaged brighter. Phases with dark and bright contrasts precipitated in austenite/ferrite boundaries. The brighter imaging phases are most likely sigma or/and chi and darker phases are most likely nitrides [10].

\section{Discussion}

As explained in the introduction, the main aim of this paper was to correlate the thermal cycles to microstructure in DSS WAAM. Therefore, this section mainly focuses on discussing this relationship based on the heat input and interlayer temperature.
Fig. 11 Microstructure along line 1 (shown in Fig. 1) in the bulk of the LHLT sample in a location reheated by several beads. Mostly growth of primary austenite can be seen
Fig. 12 Microstructure of the HHHT sample in the bulk of material reheated by several beads in line 1 (shown in Fig. 1). Mostly growth of primary austenite can be seen

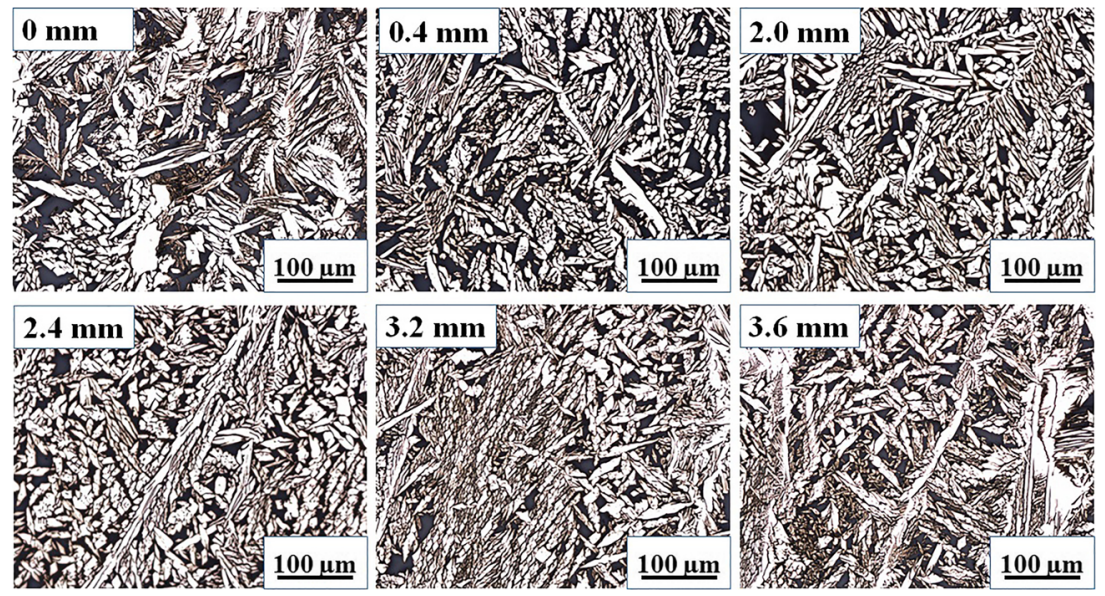

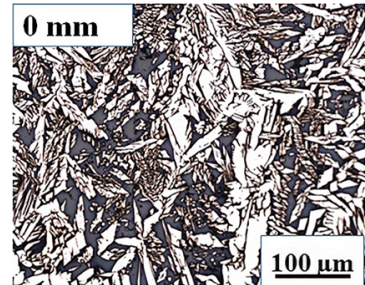

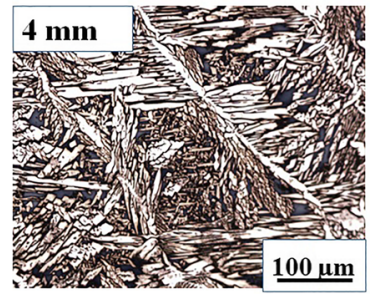

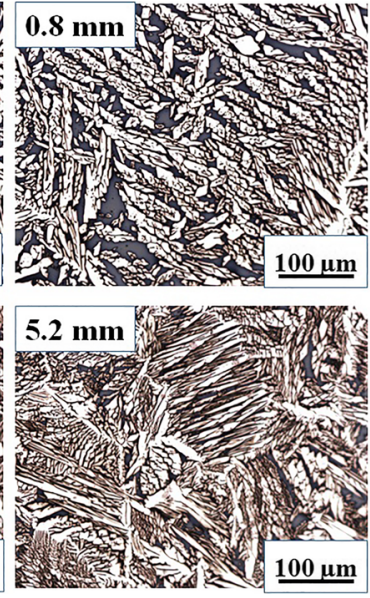

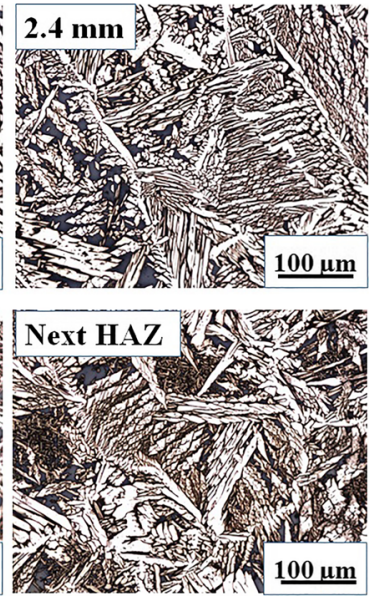




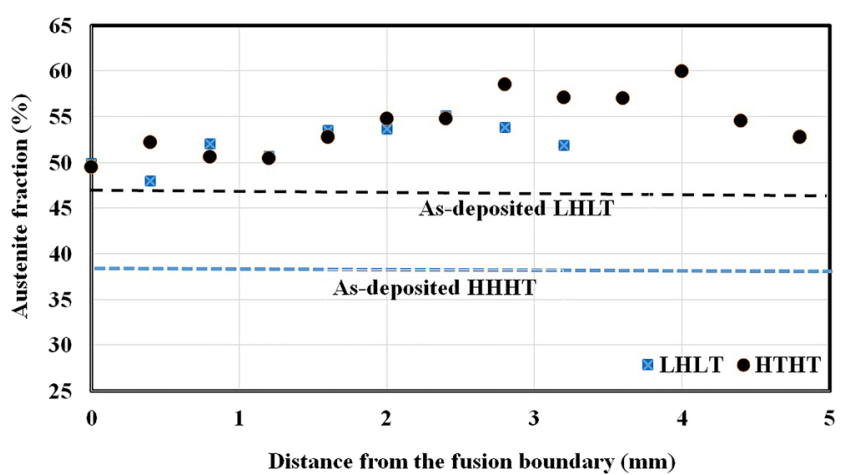

Fig. 13 Austenite fraction along line 1 (shown in Fig. 1). The HHHT sample showed the highest austenite fraction

\subsection{Thermal cycles}

Comparison of heat transfer in different layers showed that $\Delta t_{1200-800}$ is almost similar for as-deposited beads on layers 1 and 7, implying that heat transfer conditions might be similar for both cases. However, peak temperatures and time at temperatures above $400{ }^{\circ} \mathrm{C}$ were higher for layer 7 compared with layer 1 for both samples. The reason for this could be explained as follows. The as-deposited bead was mostly affected by the interlayer temperature, which was similar for both layers. Therefore, no significant changes were observed during deposition. However, in the bead reheated by the following beads, the influence of geometrical factors on heat transfer increased. In layer 1 , the big substrate cross section acted as an effective heat sink, while in layer 7 , the smaller cross section slightly reduced heat transfer and resulted in higher peak temperatures in the following layers.

\subsection{Evolution of the microstructure}

A comparison of the as-deposited beads, interestingly, showed that the LHLT bead had about $8 \%$ higher austenite fraction than the HHHT. The $\Delta t_{1200-800}$ for the HHHT sample, however, was about two times of that of the LHLT sample. In duplex stainless steels, $\Delta t_{1200-800}$ plays a crucial role in austenite formation, where the longer the cooling time, the higher the austenite fraction becomes [23], which is in contrast with the present study. The other parameter affecting the austenite/ ferrite balance is chemical composition. Nitrogen loss is a
Fig. 14 Microstructure along line 2 (shown in Fig. 1) in the bulk of the LHLT sample reheated by several beads. Growth of primary austenite and precipitation of secondary austenite can be seen
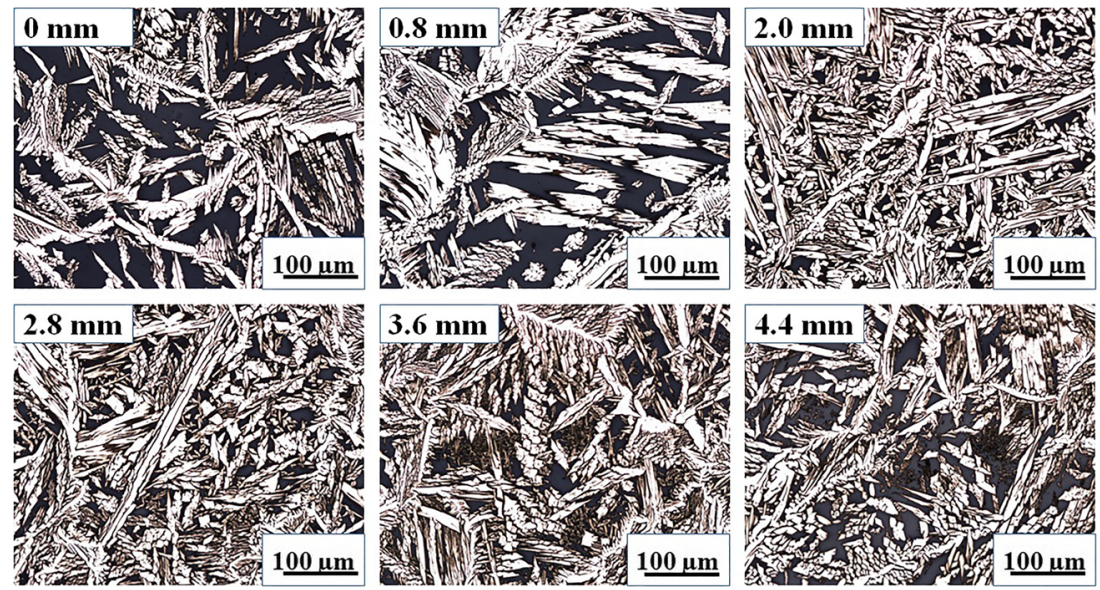

Fig. 15 Microstructure along line 2 (shown in Fig. 1) in the bulk of the HHHT sample reheated by several beads. Growth of primary austenite and precipitation of secondary austenite can be seen
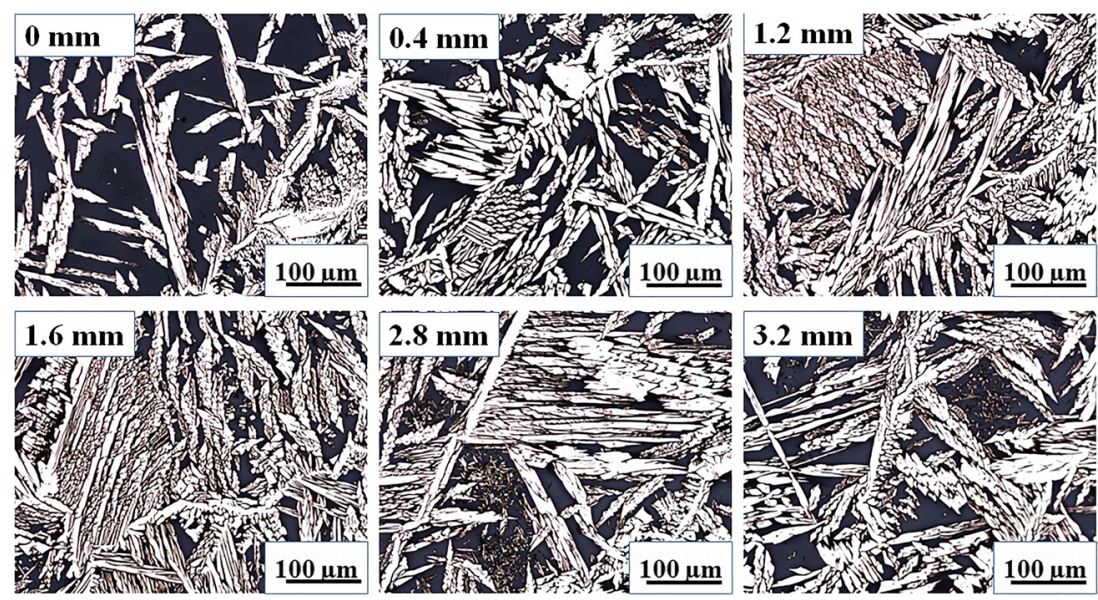


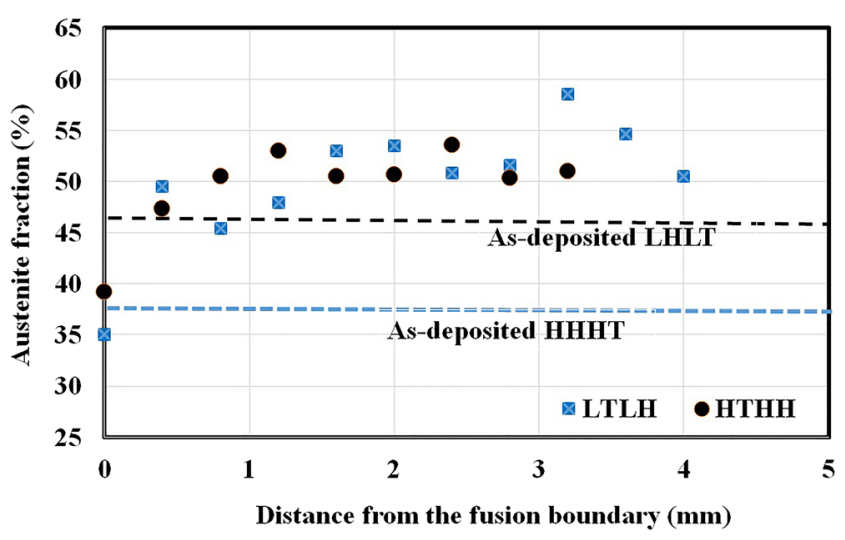

Fig. 16 Austenite fraction along line 2 (shown in Fig. 1). The LHLT and HHHT samples showed with few exceptions very similar austenite fractions

known phenomenon occurring during welding of duplex stainless steels. Nitrogen is not only a strong austenite former but also the one diffusing fastest. Hosseini et al. [12] showed that increasing the arc energy in autogenous TIG welding of super duplex stainless steels increased the nitrogen loss and decreased austenite fraction. Therefore, the most probable reason for the lower austenite fraction of the as-deposited HHHT samples is nitrogen loss.

Compared with welding for joining, it is expected to have more nitrogen loss during additive manufacturing of duplex stainless steels. Hengsbach et al. [20] reported low austenite formation even after heat treatment of selective laser melted duplex stainless steels, which was suggested to be due to nitrogen loss. The reason for a higher nitrogen loss compared with welding could be the bead formation condition and shielding. During welding, the beads are normally surrounded by other beads and base metal, which also contain nitrogen. Therefore, they can restrict the contact between the weld pool and the atmosphere (Fig. 19).

To illustrate the influence of nitrogen loss on the austenite formation, the phase equilibrium was calculated for asreceived and low-nitrogen filler material composition. For the low-nitrogen sample, $0.10 \mathrm{wt} \% \mathrm{~N}$ was considered as an example to support the discussion. As may be seen in Fig. 20, the austenite formation start temperature is lower for the lownitrogen alloy. For instance, the austenite fraction reaches $8 \%$
Fig. 17 Microstructure in the bulk of samples: a LHLT and $\mathbf{b}$ HHHT precipitates in the ferrite/ austenite phase boundaries. The precipitation is more abundant in the HHHT sample
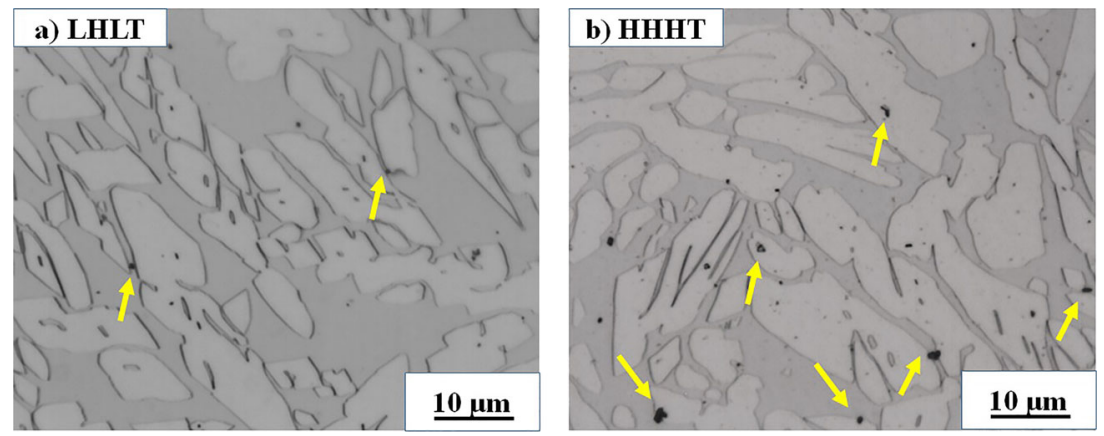

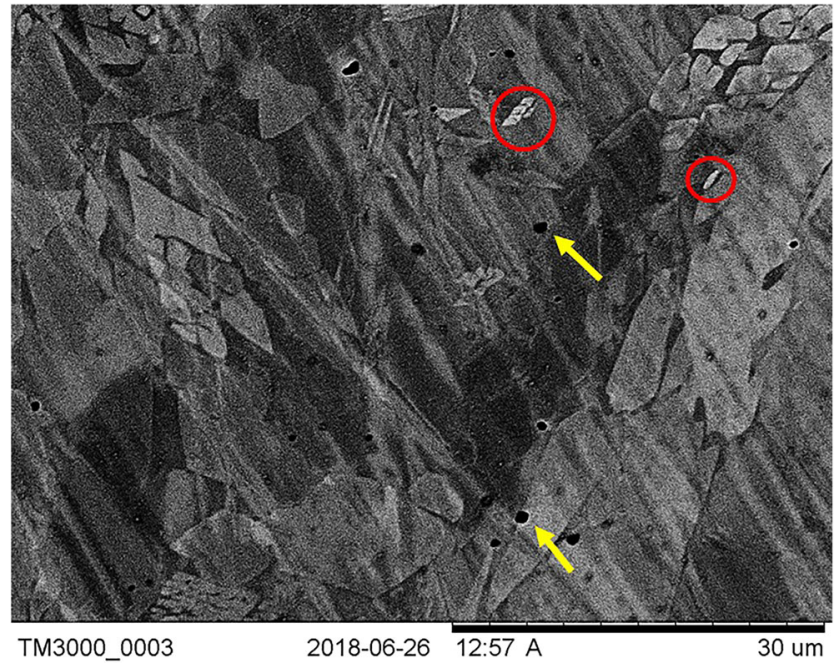

Fig. 18 Back-scattered SEM micrograph of the HHHT sample. The brighter imaging phases are most likely sigma and/or chi (inside the red cycles), and the darker imaging phases are most likely nitrides (shown by the arrows) at about $1390{ }^{\circ} \mathrm{C}$ for $0.16 \mathrm{wt} \%$ but not until at $1350{ }^{\circ} \mathrm{C}$ for $0.10 \mathrm{wt} \%$. In addition, the nitrogen loss causes the formation of a fully ferritic temperature range below solidus. These two important changes caused by nitrogen loss significantly decrease the potential of austenite formation at high temperatures. Therefore, a lower nitrogen loss resulted in more austenite formation for the LHLT sample in the as-deposited condition, as the higher nitrogen content compensated the influence of a higher cooling rate.

For one-time reheating, the situation was still the same from the viewpoint of austenite fraction, as the as-deposited austenite fraction of the LHLT sample was $8 \%$ higher than for the HHHT sample. As described, the extent of changes in the HHHT sample, however, was larger after reheating due to the higher peak temperature followed by a longer cooling time (Fig. 20).

In the bulk of samples, reheated several times by the following beads, the austenite fraction for the HHHT sample was higher for the LHLT sample along line 1 (Figs. 1 
Fig. 19 Comparison of shielding condition in multipass welding and wire-arc additive manufacturing. In welding, a smaller fraction of the weld pool surface is in contact with the atmosphere compared with that in WAAM, resulting in lesser nitrogen loss a) Welding

b) Wire-arc additive manufacturing

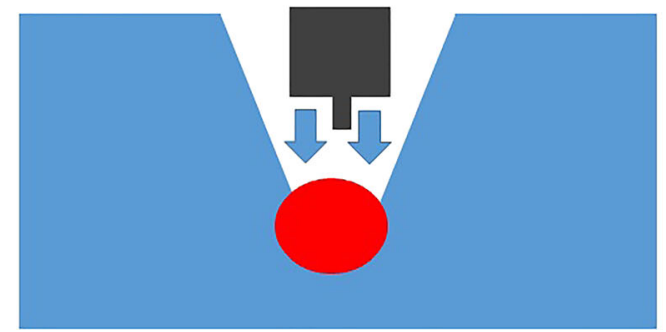

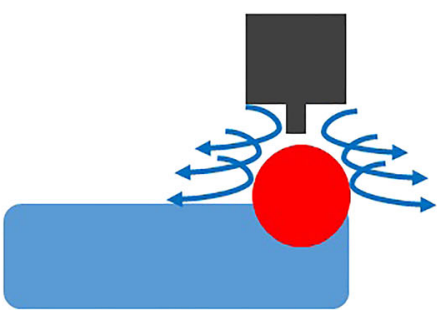

and 13) and was quite similar to that along line 2 (Fig. 14). The reason for this can also be explained by kinetics. As explained previously, the HHHT procedure resulted in longer times above $400{ }^{\circ} \mathrm{C}$, slower cooling, and more layers reaching temperatures above $600{ }^{\circ} \mathrm{C}$. These conditions all promoted austenite formation significantly. Therefore, the effects of thermal cycles were larger than the effect of the nitrogen loss and resulted in a more pronounced austenite formation in the bulk of the HHHT sample. Putz et al. [24] also reported that the austenite fraction increased with an increasing number of layers in multipass welding of type2205 duplex stainless steel using 2209 welding wire and $100 \% \mathrm{CO}_{2}$ as shielding gas. A similar observation was also reported for multipass welding of super duplex stainless steels [25].

An important result of this study was the finding of a pattern that was valid for both the LHLT and the HHHT samples. This pattern was the result of the influence of reheating passes and peak temperatures. Line 1 was located where at least three passes directly increased the peak temperature above $800{ }^{\circ} \mathrm{C}$. Line 2 , on the other hand, mostly had a microstructure formed during reheating by the pass directly above. However, other passes obviously increased the austenite fraction compared with that found after one-time reheating. This was especially the case for the HHHT sample due to the longer time spent at higher temperatures as well as higher peak temperatures.

As explained, the HHHT sample with lower austenite fractions in the as-deposited condition achieved a higher austenite fraction in the bulk due to the long reheating. However, this long reheating at a high temperature caused the precipitation of secondary phases. Karlsson et al. [26] studied sigma phase formation in $22 \% \mathrm{Cr}$ DSS weld metal and showed that only $1 \mathrm{~min}$ of reheating at the nose of the time-temperature precipitation diagram would form about $1 \%$ sigma phases. Therefore, the precipitation of intermetallics is expected in the time range of this study. In addition, multiple reheating in the critical secondary phase precipitation temperature range also promoted their nucleation and growth [27].

\section{a) As-received filler}

Fe-23.1Cr-0.05Cu-1.55Mn-3.1Mo-8.64Ni-0.48Si-0.012C-0.16N wt(\%)

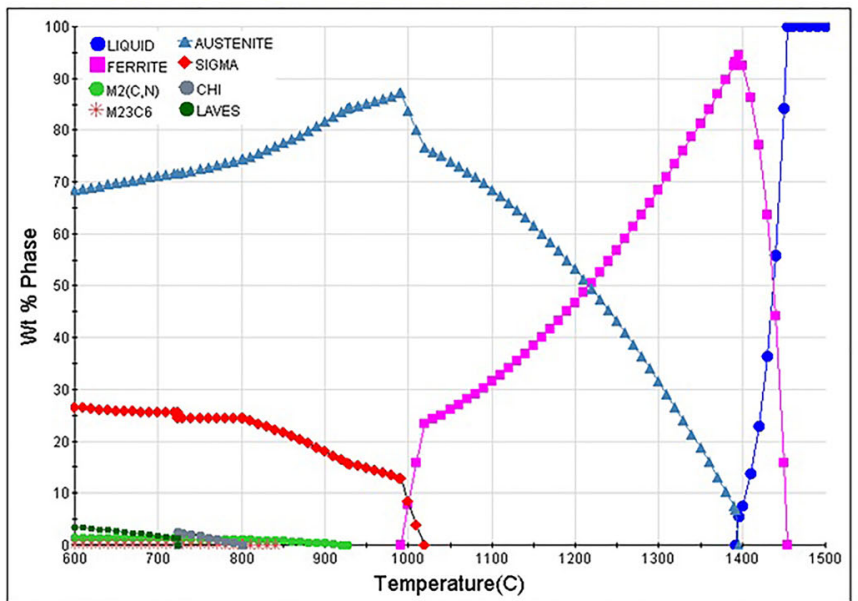

\section{b) Possible nitrogen loss}

\section{Fe-23.1Cr-0.05Cu-1.55Mn-3.1Mo-8.64Ni-0.48Si-0.012C-0.1N wt(\%)}

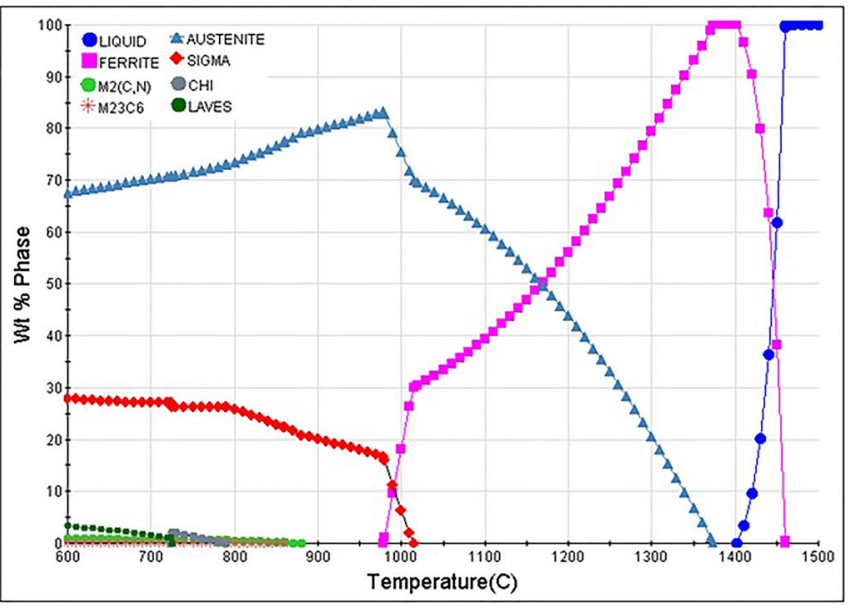

Fig. 20 The equilibrium phase fraction of filler metal for a as-received filler with $0.16 \mathrm{wt} \% \mathrm{~N}$ and $\mathbf{b}$ as-deposited filler with $0.10 \mathrm{wt} \% \mathrm{~N}$ due to nitrogen loss 


\subsection{Final comments}

Wire-arc additive manufacturing of type-2209 DSS showed that using GMAW with quite different process parameters and high interlayer temperature produced acceptable microstructures. The next step for this study is to investigate the mechanical properties and corrosion resistance to investigate the possible influences of precipitates on the final properties.

The thermal cycle analysis employed in this study provided unique information about how the addition of different passes with different arc energies, sequences, and interlayer temperatures influenced resulting thermal cycles. This information can be used to develop and verify models for heat transfer during WAAM.

A low austenite fraction has been observed for SLM samples even after heat treatment in previous studies [20], which is in good agreement with the low austenite fraction observed in the as-deposited microstructure. This is a clear indication of nitrogen loss during AM processes. Further studies are however required to measure the nitrogen loss in WAAM. A separate study is also needed to develop a model for nitrogen loss based on the process parameters similar to those introduced for GTAW [12]. In addition, the influence of nitrogen addition to the shielding gas on the as-deposited microstructure with different arc energies could be the subject of another study.

From the view of the industrial applications, it was a prestudy for fabrication of DSS using WAAM ultimately aiming at industrial applications. The final aim is therefore to develop a continuously running system to minimize the production time and have the highest deposition rate using a standard GMAW power source. Local cooling and a wider process variable window could help achieve this goal.

\section{Conclusions}

Wire-arc additive manufacturing of type-2209 duplex stainless steel using gas-metal arc welding was performed to study the relationship between thermal cycles and as-built microstructure. Thermal cycles were recorded using thermocouples attached on the substrates and previously built layers. Two samples were fabricated using $0.6 \mathrm{~kJ} / \mathrm{mm}$ arc energy and $150{ }^{\circ} \mathrm{C}$ interlayer temperature (LHLT) as well as $0.8 \mathrm{~kJ} / \mathrm{mm}$ arc energy and $250{ }^{\circ} \mathrm{C}$ interlayer temperature (HHHT). The concluding remarks are as follows:

1- Similar geometries were produced with 14 layers and 4 beads in each layer with the LHLT procedure, as with 15 layers and 3 beads in each layer for the HHHT procedure. The total production time was $183 \mathrm{~min}$ for the LHLT and 110 min for the HHHT procedure.

2- The $\Delta t_{1200-800}$ for as-deposited beads was about $4 \mathrm{~s}$ for the LHLT procedure and $8 \mathrm{~s}$ for the HHHT procedure.
The time above $400{ }^{\circ} \mathrm{C}$ for the as-deposited layer was about $20 \mathrm{~s}$ longer for the HHHT sample while it experienced a heating from a lower number of passes compared with the LHLT sample. This time is longer for upper layers of the built sample.

3- The HHHT procedure caused higher peak temperatures in the previously deposited layers, where about 6 layers reached temperatures above $600{ }^{\circ} \mathrm{C}$ in the HHHT sample, while only 4 layers did in the LHLT sample.

4- As-deposited austenite fraction was $8 \%$ higher for the LHLT sample, which is hypothesized to be the result of nitrogen loss. One-time reheating increased the austenite fraction up to $10 \%$ at some locations in the reheated beads of the LHLT and HHHT samples.

5- Austenite fractions followed a pattern in the bulk of both samples. In the center of each bead, mostly secondary austenite grew. In the corner of the beads reheated several times at higher peak temperatures, primary austenite and coarse secondary austenite were observed mostly.

6- After reheating several times by the following beads, both the LHLT and HHHT samples showed almost the same austenite fraction.

7- Nitrides were found in one-time-reheated beads close to their fusion boundary with the as-deposited bead. Sigma, chi, and nitrides were also detected in the bulk of samples, reheated several times by the following beads. Their fraction was higher for the HHHT sample due to longer reheating at high peak temperatures.

Open Access This article is distributed under the terms of the Creative Commons Attribution 4.0 International License (http:// creativecommons.org/licenses/by/4.0/), which permits unrestricted use, distribution, and reproduction in any medium, provided you give appropriate credit to the original author(s) and the source, provide a link to the Creative Commons license, and indicate if changes were made.

\section{References}

1. Lippold JC, Kotecki DJ (2005) Welding metallurgy and weldability of stainless steels. In: Lippold JC, Kotecki DJ (eds) Welding metallurgy and weldability of stainless steels. Wiley-VCH, p 376 ISBN 0-471-47379-0

2. Karlsson L (2012) Welding of duplex stainless steels - a review of current recommendations. Weld World 56(5):6

3. Mraz L, Matsuda F, Kikuchi Y, Sakamoto N, Kawaguchi S (1994) Temper embrittlement of cast duplex stainless steels after long-term aging. Transaction of JWRI 23(2):10

4. Matias JVS, Tavares SSM, Pardal JM, Ribeiro RSdA (2017) Embrittlement and corrosion decay of a cast duplex stainless steel. Mater Res (AHEAD):0-0

5. Martins M, Casteletti LC (2009) Sigma phase morphologies in cast and aged super duplex stainless steel. Mater Charact 60(8):792-795

6. Chung H (1992) Aging and life prediction of cast duplex stainless steel components. Int J Press Vessel Pip 50(1-3):179-213 
7. Dobrzanski L, Brytan Z, Grande MA, Rosso M (2007) Properties of duplex stainless steels made by powder metallurgy. Arch Mater Sci 218:218

8. Posch G, Chladil K, Chladil H (2017) Material properties of CMT - metal additive manufactured duplex stainless steel bladelike geometries. Weld World 61(5):873-882

9. Davidson K, Singamneni S (2016) Selective laser melting of duplex stainless steel powders: an investigation. Mater Manuf Process 31(12):1543-1555

10. Hosseini VA, Karlsson L, Örnek C, Reccagni P, Wessman S, Engelberg D (2018) Functionally graded microstructure of super duplex stainless steel. Mater Charact 139:11

11. Messer B, Oprea V, Wright A (2007) Duplex stainless steel welding: best practices. Stainless Steel World:53-63

12. Hosseini VA, Wessman S, Hurtig K, Karlsson L (2016) Nitrogen loss and effects on microstructure in multipass TIG welding of a super duplex stainless steel. Mater Des 98:88-97

13. Westin E, Johansson M, Pettersson R (2013) Effect of nitrogencontaining shielding and backing gas on the pitting corrosion resistance of welded lean duplex stainless steel LDX $2101 \circledast(E N ~ 1.4162$, UNS S32101). Weld World 57(4):467-476

14. A Hosseini V, Karlsson L, Engelberg D, Wessman S (2018) Timetemperature-precipitation and property diagrams for super duplex stainless steel weld metals. Weld World 62:517-533. https://doi. org/10.1007/s40194-018-0548-Z

15. Pettersson N, Pettersson RFA, Wessman S (2015) Precipitation of chromium nitrides in the super duplex stainless steel 2507. Metall Mater Trans A 46(3):1062-1072

16. Liao J (2001) Nitride precipitation in weld HAZs of a duplex stainless steel. ISIJ Int 41(5):460-467

17. Karlsson L (1995) Welding duplex and super duplex stainless steels. Anti-Corrosion Methods and Materials 42(6):30-35

18. Ding D, Pan Z, Cuiuri D, Li H (2015) Wire-feed additive manufacturing of metal components: technologies, developments and future interests. Int J Adv Manuf Technol 81(1-4):465-481

19. Frazier WE (2014) Metal additive manufacturing: a review. J Mater Eng Perform 23(6):1917-1928
20. Hengsbach F, Koppa P, Duschik K, Holzweissig MJ, Burns M, Nellesen J, Tillmann W, Tröster T, Hoyer K-P, Schaper M (2017) Duplex stainless steel fabricated by selective laser meltingmicrostructural and mechanical properties. Mater Des 133:136-142

21. Eriksson M, Lervåg M, Sørensen C, Robertstad A, Brønstad BM, Nyhus B, Aune R, Ren X, Akselsen OM (2018) Additive manufacture of superduplex stainless steel using WAAM. In: MATEC Web of Conferences. EDP Sciences, p 03014

22. Hosseini VA, Hurtig K, Eyzop D, Östberg A, Janiak P, Karlsson L (2018) Ferrite content measurement in super duplex stainless steel welds. Weld World:1-13

23. Yang Y, Yan B, Li J, Wang J (2011) The effect of large heat input on the microstructure and corrosion behaviour of simulated heat affected zone in 2205 duplex stainless steel. Corros Sci 53(11):37563763

24. Putz A, Althuber M, Zelić A, Westin EM, Willidal T, Enzinger N (2018) Optimized method for measurement of ferrite content in multi-pass duplex stainless steel welds (IX-8644-18). Paper presented at the IIW Intermediate Meeting-C IX-H, Bali

25. Bermejo MAV, Eyzop D, Karlsson L, Svensson L-E, Hurtig K (2017) Influence of multi-pass welding on the microstructure and properties of superduplex stainless steels (IIW Doc IX-2607-17). Paper presented at the IIW Annual Assembly, China

26. Karlsson L, Ryen L, Pak S (1995) Precipitation of intermetallic phases in $22 \% \mathrm{Cr}$ duplex stainless weld metals. Welding JournalIncluding Welding Research Supplement 74(1):28-38

27. Hosseini VA, Bermejo MAV, Gårdstam J, Hurtig K, Karlsson L (2016) Influence of multiple thermal cycles on microstructure of heat-affected zone in TIG-welded super duplex stainless steel. Weld World 60(2):233-245

Publisher's note Springer Nature remains neutral with regard to jurisdictional claims in published maps and institutional affiliations. 